\title{
The assessment of water loss from a damaged distribution pipe using the FEFLOW software
}

\author{
Małgorzata Iwanek ${ }^{1, *}$, and Pawet Suchorab ${ }^{1}$ \\ ${ }^{1}$ Lublin University of Technology, Faculty of Environmental Engineering, Nadbystrzycka 40 B, 20-618 Lublin, Poland
}

\begin{abstract}
Common reasons of real water loss in distribution systems are leakages caused by the failures or pipe breakages. Depending on the intensity of leakage from a damaged buried pipe, water can flow to the soil surface just after the failure occurs, much later or never at all. The localization of the place where the pipe breakage occurs is relatively easy when water outflow occurs on the soil surface. The volume of lost water strongly depends on the time it takes to localize the place of a pipe breakage. The aim of this paper was to predict the volume of water lost between the moment of a failure occurring and the moment of water outflow on the soil surface, during a prospective failure in a distribution system. The basis of the analysis was a numerical simulation of a water pipe failure using the FEFLOW v. 5.3 software (Finite Element subsurface FLOW systems) for a real middlesized distribution system. Simulations were conducted for variants depending on pipes' diameter $(80 \div 200 \mathrm{~mm})$ for minimal and maximal hydraulic pressure head in the system $(20.14$ and $60.41 \mathrm{~m} \mathrm{H}_{2} \mathrm{O}$, respectively). FEFLOW software application enabled to select places in the water system where possible failures would be difficult to detect.
\end{abstract}

\section{Introduction}

Water pipe breakages are an inherent part of the exploitation process of every water distribution system (WDS). Except the main consequence of pipe failure being the limitation of a water delivery to customers, pipe breakages are also common reasons of real water losses. According to World Bank data, 45 million $\mathrm{m}^{3}$ of water is lost each day only in developing countries, due to WDS failures [1]. Water can be lost through burst leakages with a significant pressure loss or through background leakages. [2]. Burst leakages are relatively easy to detect as their effects are usually easy to notice (e.g. water outflow to the soil surface, suffusion holes, a lack of water delivery). Depending on the intensity of leakage from a damaged buried pipe, water can flow to the soil surface just after the failure occurrence or much later. It is also possible that water will never outflow to the soil surface, especially from hard-to-detect background leakages [3]. As the volume of lost water strongly depends on the pressure head and the time taken to localize the place of a pipe breakage, over the past decades numerous leakage detection methods and tools have been developed.

One of the most considerable ways to localize the place of pipe breakage is the usage of noise correlators, geophones, ground-penetrating radars, etc. The application of hardware tools is usually highly effective but also highly time-consuming and not applicable in realtime WDS diagnostics [4]. The other way to detect water leakage is the use of software methods. The most popular indirect leakage diagnosis methods are: Negative Pressure
Wave method (NPW), Minimum Night Flow method (MNF) [5] and hydraulic modelling in combination with Supervisory Control And Data Acquisition system (SCADA). Moreover, the best results in water leakage detection are achieved by combining hardware and software methods - the area of possible water leakage is restricted thanks to software applications and then the leakage is localised by hardware tools.

Quick and precise detection and location of a pipe breakage results in relatively small water losses and therefore in small economic loss. However, water companies endeavour to limit the amount of lost water to an economically reasonable level. The optimal water loss level is defined as the amount of lost water of which financial value is smaller than the costs of water leakage minimising efforts [6]. That is why water companies decide to only repair pipe breakages that cause burst leakages with visible effects, often ignoring background leakages.

The aim of this paper was to select places in the analysed water system where possible pipe failures would be difficult to detect, and to predict the volume of water lost between the moment a failure occurs and the moment of water outflow to the soil surface. It was expected that the results could support the decisive process made by the water company to whether the breakage in a selected area is of a high or low repair priority. The basis of the analysis was a numerical simulation of a water pipe failure using the FEFLOW software (Finite Element subsurface FLOW systems) for a real middle-sized distribution system. Simulations were conducted for variants depending on the

\footnotetext{
Corresponding author: M.Iwanek@wis.pol.lublin.pl
} 
pipes' diameter for minimal and maximal hydraulic pressure head in the system.

\section{Methodology}

The analysis of water losses from a damaged water pipe was performed for the real WDS in the Lublin Region. It is a middle-size water supply system of an urban character, providing water to approx. 10000 customers. The branched-looped water network is made of both traditional materials (steel, cast iron, asbestos-cement) $55.32 \%$, as well as from plastic pipes (PVC, PE) $44.68 \%$. Pipe diameters vary from DN80 up to DN200. The total length of the water network is approx. $54 \mathrm{~km}$. The geometrical structure of an analysed WDS with diameter differentiation is presented in figure 1.

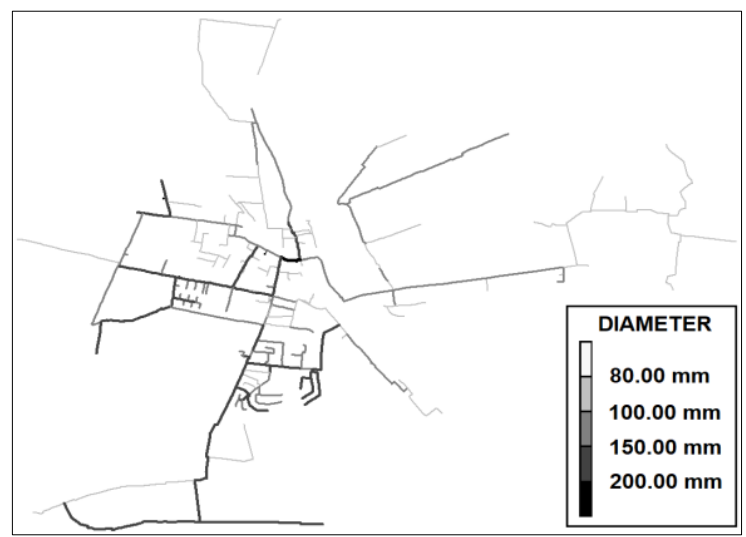

Fig. 1. Geometrical structure of the analysed WDS.

The analysed WDS is operated in non-zone configuration, but with relatively small daily pressure head variations in particular water supply nodes (e.g. pressure head amplitude in reference nodes equals to $3 \div 4 \mathrm{~m} \mathrm{H}_{2} \mathrm{O}$ maximum). However, the pressure head in the WDS in general varies from minimal acceptable levels $\left(20 \mathrm{~m} \mathrm{H}_{2} \mathrm{O}\right)$ up to maximal acceptable levels $\left(60 \mathrm{~m} \mathrm{H}_{2} \mathrm{O}\right)$. The contour plot of a hydraulic pressure head is presented in figure 2. "A" mark stands for the node with the lowest pressure head (20.14 $\left.\mathrm{m} \mathrm{H}_{2} \mathrm{O}\right)$, and "B" mark identifies the node with the highest pressure head $\left(60.41 \mathrm{~m} \mathrm{H}_{2} \mathrm{O}\right)$.

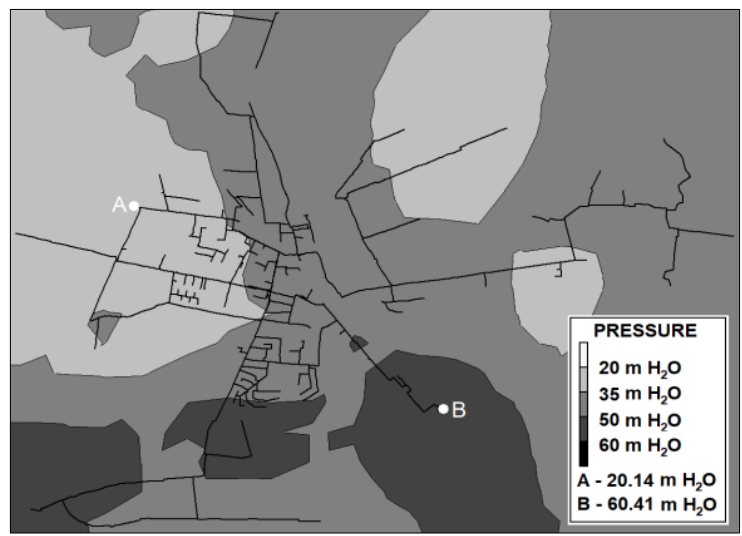

Fig. 2. Contour plot of a hydraulic pressure head in the analysed WDS.
Simulations of water losses were conducted for 12 different variants depending on the pipes' diameter and hydraulic pressure head in the system. The water supply network is composed of 4 different-sized traditional pipes (DN/ID 80, 100, 150, 200) and 2 different-sized plastic pipes (DN/OD 110, 160). Conducted variants of simulations included pipes of all size diameters in the analysed WDS and two extreme values of hydraulic pressure head inside pipes. Numerical simulations of a water pipe failure were performed in FEFLOW v. 5.3 software. It is a widely applied tool in simulations of water, pollutants, mass and heat transport in porous media and fractured media in two (2D) and three dimensional (3D) modelling. FEFLOW is based on Finite Elements/Volumes Methods (FEM/FVM) used to solve groundwater flow equation of both saturated and unsaturated conditions. The software was developed in ANSI $\mathrm{C} / \mathrm{C}++$ which allowed its application in Windows and Linux environments [7].

To simulate water pipe breakage in FEFLOW software, 2-dimentional soil profile was used, reflecting the cross section of a real water pipe environment in an excavation. Dimensions of a soil profile: $20 \mathrm{~m} \times 5 \mathrm{~m}$. The cross section of a soil profile with water pipe is presented in figure 3 .

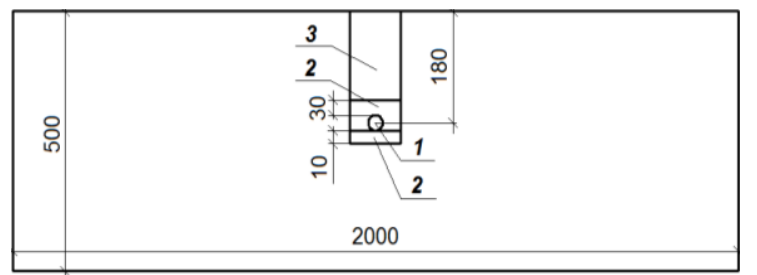

Fig. 3. Scheme of cross section of soil profile with the water pipe ( 1 - inner pipe diameter, 2 - sand, 3 - natural ground in and around the excavation; dimensions in $\mathrm{cm}$ ).

Properties of unsaturated soils were characterized by the van Genuchten (1980) relationship given by formula 1. Hydraulic parameters of simulated soils are presented in table 1.

$$
\begin{gathered}
K=K_{S} S^{l}\left\lfloor 1-\left(1-S^{\frac{1}{m}}\right)^{m}\right\rfloor^{2} \\
S=\frac{\theta-\theta_{r}}{\theta_{S}-\theta_{r}}=\frac{1}{\left[1+(\alpha H)^{n}\right]^{m}} \\
m=1-\frac{1}{n}
\end{gathered}
$$

where:

$K$ - hydraulic conductivity, $\mathrm{m} / \mathrm{s}$

$K_{S}$ - saturated hydraulic conductivity coefficient, $\mathrm{m} / \mathrm{s}$

$S$ - degree of saturation given by formula (2)

$l$ - fitting parameter [9]

$m$ - fitting parameter given by formula (3)

$\theta-$ volumetric water content, $\mathrm{m}^{3} / \mathrm{m}^{3}$

$\theta_{r}-$ residual volumetric water content, $\mathrm{m}^{3} / \mathrm{m}^{3}$

$\theta_{s}$ - saturated volumetric water content, $\mathrm{m}^{3} / \mathrm{m}^{3}$

$\alpha, n$ - fitting parameters, $1 / \mathrm{m},-$

$H$ - pressure head, $\mathrm{m}$ 
Table 1. Hydraulic parameters of soils used in simulations

\begin{tabular}{|c|c|c|c|c|c|}
\hline $\begin{array}{c}\text { Soil } \\
\text { (according to } \\
\text { Fig. 3) }\end{array}$ & $\boldsymbol{S}$ & $\boldsymbol{K S}$ & $\boldsymbol{P}$ & $\boldsymbol{\alpha}$ & $\boldsymbol{n}$ \\
\cline { 2 - 6 } & - & $\begin{array}{c}\mathbf{1 0} \\
\mathbf{m} / \mathbf{s}\end{array}$ & $\begin{array}{c}\mathbf{\%} \\
\text { (vol.) }\end{array}$ & $\mathbf{1 / m}$ & - \\
\hline $\begin{array}{c}\text { No 3 in and } \\
\text { around the } \\
\text { excavation }\end{array}$ & 0.442 & 0.488 & 0.217 & 2.968 & 1.652 \\
\hline $\begin{array}{c}\text { No 2 in the } \\
\text { excavation }\end{array}$ & 0.323 & 0.626 & 0.366 & 2.800 & 2.239 \\
\hline
\end{tabular}

$P-$ porosity

Two different types of boundary conditions were used in the model: the first-type (Dirichlet) boundary condition on the leak $\left(H=20.14 \mathrm{~m} \mathrm{H}_{2} \mathrm{O}\right.$ or $\left.H=60.41 \mathrm{~m} \mathrm{H}_{2} \mathrm{O}\right)$ and on the bottom of a soil profile $\left(H=-1 \mathrm{~m} \mathrm{H}_{2} \mathrm{O}\right.$ - specific value in a water retention curve), as well as the secondtype (Neumann) as a boundary condition on the top of a soil profile. A scheme of soil profile with an exemplary finite element mesh (12843 elements for DN200) and boundary conditions are presented in figure 4 .

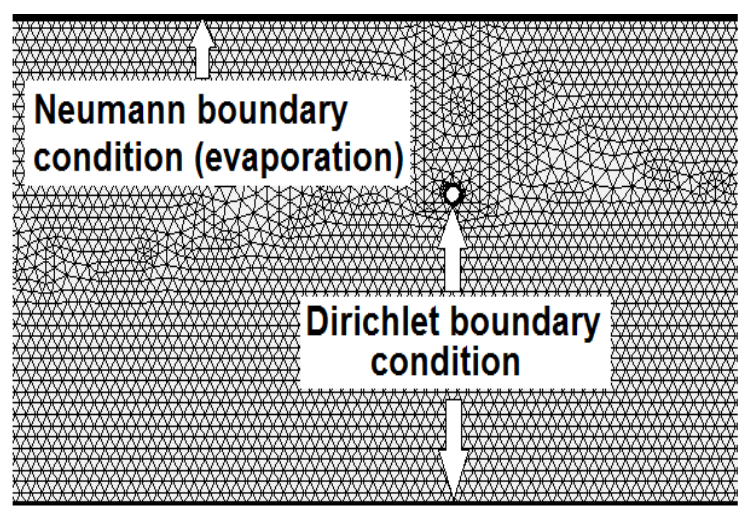

Fig. 4. Boundary conditions and finite element mesh of the exemplary analysed soil profile (for pipe diameter DN200).

The breakage of a pipe was shown as a circular $5 \mathrm{~mm}$ unsealing of the pipe. That assumption was made on the basis of results of numerical investigations $[8,9]$ and laboratory investigations [10] of water outflow to the soil surface after the water pipe breakage. Pipes' diameters (nominal (DN) and inner (ID)) and areas of a leak are presented in table 2 .

Table 2. Pipes parameters and leakage areas.

\begin{tabular}{|c|c|c|c|c|}
\hline $\begin{array}{c}\text { DN } \\
(\mathbf{m m})\end{array}$ & $\underset{(\mathbf{m m})}{\text { ID }}$ & $\begin{array}{c}\text { Wall } \\
\text { thicknes } \\
\text { S } \\
(\mathbf{m m})\end{array}$ & $\begin{array}{c}\text { Unsealin } \\
\text { g width } \\
\text { (mm) }\end{array}$ & $\begin{array}{c}\text { Unsealin } \\
\text { g area } \\
\left(\mathbf{m}^{2}\right)\end{array}$ \\
\hline 80 & 80 & $\mathrm{n} / \mathrm{a}$ & \multirow{6}{*}{5} & 0.0025 \\
\hline 110 & 97.1 & 6.45 & & 0.0030 \\
\hline 100 & 100 & $\mathrm{n} / \mathrm{a}$ & & 0.0031 \\
\hline 160 & 141.2 & 9.4 & & 0.0044 \\
\hline 150 & 150 & $\mathrm{n} / \mathrm{a}$ & & 0.0047 \\
\hline 200 & 200 & $\mathrm{n} / \mathrm{a}$ & & 0.0063 \\
\hline
\end{tabular}

The result of each FEFLOW simulation variant was the time of water outflow to the soil surface. Based on obtained results, the total volume of lost water during the moment of a pipe breakage and water surface outflow was calculated using formula (4) [11].

$$
V=Q \cdot t=A \cdot C_{d} \cdot \sqrt{2 \cdot g \cdot H} \cdot t
$$

where:

$V$ - volume of lost water, $\mathrm{m}^{3}$

$Q$ - unitary water outflow, $\mathrm{m}^{3} / \mathrm{s}$

$t$ - time of water outflow to the soil surface, $\mathrm{s}$

$A$ - leak area, $\mathrm{m}^{2}$

$C_{d}$ - discharge coefficient, -

$g-$ gravitational acceleration, $\mathrm{m} / \mathrm{s}^{2}$

$H$ - pressure head, $\mathrm{m}$

The $C_{d}$ coefficient, given by formula 5 - symbols as in formula 4 , is defined as the ratio between the actual flow discharge $\left(Q_{a c t}\right)$ and theoretical discharge resulting from the Torricelli's theorem.

$$
C_{d}=\frac{Q_{\text {act }}}{A \cdot \sqrt{2 \cdot g \cdot H}}
$$

$Q_{a c t}$ was estimated on a basis of the numerical simulation in the FEFLOW software, assuming outflow of water through an orifice to sand medium (parameters as for soil No 2 in the excavation - tab.1.). Details about the profile are given in figure 5 .

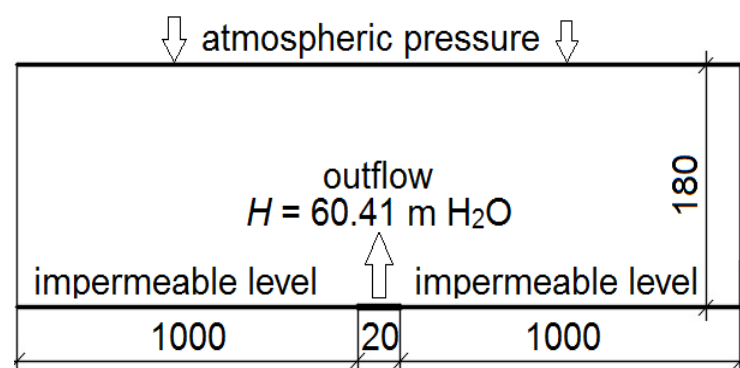

Fig. 5. Scheme of cross-section of soil profile to estimate $C_{d}$ coefficient (dimensions in $\mathrm{cm}$ ).

The final result of the study was the priority of the estimation of areas in which the water supply system had the highest possibility of hard-to-detect background leakages. Priorities were accepted in reference to the time between water pipe breakage and water outflow to the soil surface. Three types of water losses zones priorities were estimated:

- high priority where potential background leakages will be difficult to observe and where it is highly recommended to systematically implement software and hardware leakage detection methods,

- medium priority - implementation of hardware leakage detection methods is recommended occasionally,

- low priority - only software leakage detection methods are recommended due to the high possibility of water outflow to the soil surface together with significant pressure loss.

Investigations were carried out in the following order: estimation of a $C_{d}$ coefficient, simulation of time of water outflow to the soil surface in FEFLOW software, the 
calculation of the amount of lost water during the pipe breakage identification of water supply priority zones.

\section{Results}

In accordance to presented methodology, the calculated value of discharge coefficient $C_{d}$ equals 0.166 . In water outflow to the soil medium, the efficiency of $C_{d}$ is clearly lower when compared to the outflow to the atmosphere, because of higher flow resistance and contraction.

Results of numerical simulations of time between the moment of water leakage from a damaged pipe and the water outflow occurrence on the soil surface are presented in table 3. As expected, the smaller leak area (pipe diameter) and pressure head, the higher value of time. The extreme result was observed for the case of diameter DN80 and pressure head $H=20.14 \mathrm{~m} \mathrm{H}_{2} \mathrm{O}$ - time of water outflow equalled nearly 14 minutes. On the contrary, the shortest time was noted in the case of diameter DN200 and pressure head $60.41 \mathrm{~m} \mathrm{H}_{2} \mathrm{O}$ - time equalled 2.38 minutes. Exemplary saturation of soil profiles in moments of water outflows for extreme mentioned variants are presented in figures 6 and 7.

The amount of lost water due to pipe breakage is also presented in table 3 . The case of the highest time value of water outflow on the soil surface does not result in the greatest amount of lost water as the volume of lost water depends also on leak area and the pressure head. The extreme case of the amount of lost water is DN200 and $H=2.14 \mathrm{~m} \mathrm{H}_{2} \mathrm{O}$ in which during $7.65 \mathrm{~min}$ of water leakage, over $9.5 \mathrm{~m}^{3}$ of water is lost into the ground. Considering all the factors influencing the volume of lost water, the general observed trend is that the bigger the leak area for the same value of pressure head, the bigger the amount of volume of lost water. However, as the bigger pressure head results in shorter water outflow time on the soil surface, volumes of lost water are smaller for the pressure head equalled to $60.41 \mathrm{~m} \mathrm{H}_{2} \mathrm{O}$ than for $20.14 \mathrm{~m} \mathrm{H}_{2} \mathrm{O}$.

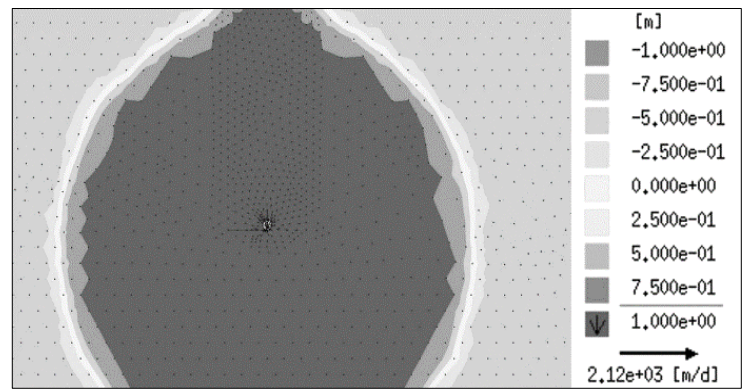

Fig. 6. Saturation of soil profile in the moment of water outflow (DN80, $H=20.14 \mathrm{~m} \mathrm{H}_{2} \mathrm{O}$ ).

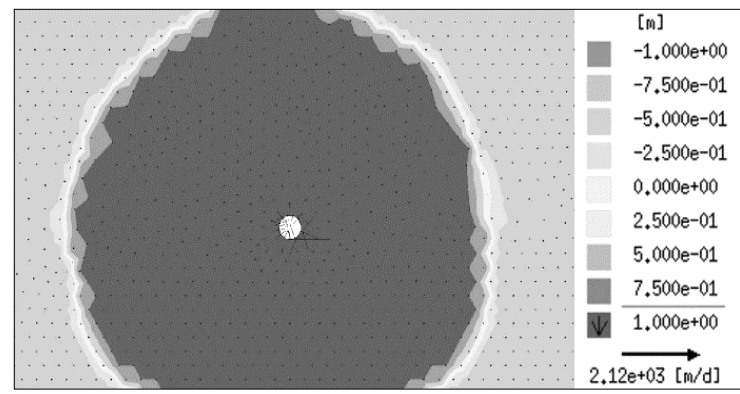

Fig. 7. Saturation of soil profile in the moment of water outflow (DN200, $\mathrm{H}=60.41 \mathrm{~m} \mathrm{H}_{2} \mathrm{O}$ ).

Graphical illustrations of dependence between the leak area, pressure head and the time of water outflow and volume of lost water are presented in figure 8 . General observed dependence is that the lower the pressure head and smaller the leak area, the higher the water time outflow and therefore the bigger water losses.

Table 3. Simulation results of water time outflow and volume of lost water.

\begin{tabular}{|c|c|c|c|c|c|c|c|c|c|c|}
\hline \multirow{2}{*}{\multicolumn{2}{|c|}{$\begin{array}{c}\begin{array}{c}\text { Pressure head } \\
\left(\mathrm{m} \mathrm{H}_{2} \mathrm{O}\right)\end{array} \\
\text { Parameter }\end{array}$}} & \multicolumn{2}{|c|}{20.14} & \multicolumn{2}{|c|}{60.41} & \multirow{2}{*}{$C_{d}$} & 20.14 & 60.41 & 20.14 & 60.41 \\
\hline & & \multicolumn{2}{|c|}{$t$} & \multicolumn{2}{|c|}{$t$} & & \multicolumn{2}{|c|}{$Q$} & \multicolumn{2}{|c|}{$\boldsymbol{V}$} \\
\hline $\begin{array}{c}\text { DN } \\
(\mathbf{m m} \\
)\end{array}$ & $\begin{array}{c}\text { ID } \\
(\mathbf{m m})\end{array}$ & $\mathbf{S}$ & $\min$ & $\mathbf{s}$ & $\min$ & - & $\mathrm{m}^{3} / \mathrm{s}$ & $\mathrm{m}^{3} / \mathrm{s}$ & $\mathbf{m}^{3}$ & $\mathbf{m}^{3}$ \\
\hline 80 & 80 & 839.14 & 13.99 & 198.55 & 3.31 & & 0.0083 & 0.0144 & 6.96 & 2.85 \\
\hline 110 & 97.1 & 662.46 & 11.04 & 183.92 & 3.07 & & 0.0101 & 0.0174 & 6.67 & 3.21 \\
\hline 100 & 100 & 608.24 & 10.14 & 160.28 & 2.67 & & 0.0137 & 0.0180 & 6.31 & 2.88 \\
\hline 160 & 141.2 & 536.75 & 8.95 & 153.02 & 2.55 & & 0.0146 & 0.0238 & 7.86 & 3.88 \\
\hline 150 & 150 & 520.49 & 8.67 & 151.14 & 2.52 & & 0.0156 & 0.0269 & 8.10 & 4.07 \\
\hline 200 & 200 & 459.17 & 7.65 & 142.90 & 2.38 & & 0.0207 & 0.0359 & 9.53 & 5.13 \\
\hline
\end{tabular}




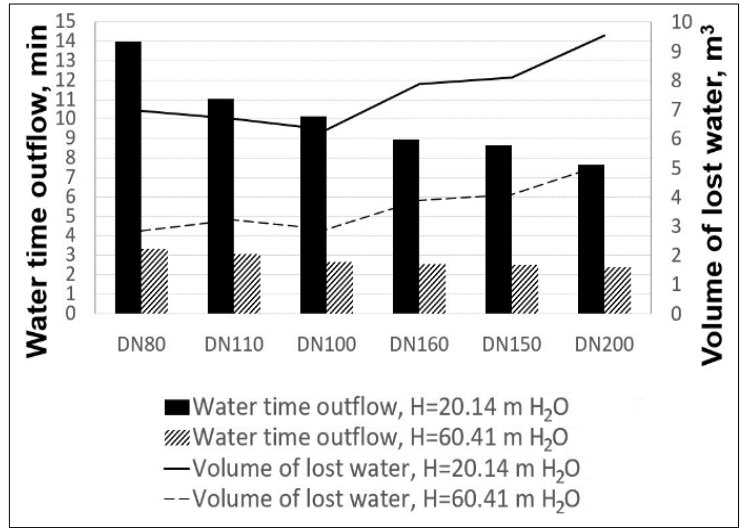

Fig. 8. Time of water outflow and the volume of lost water for different pipe diameters and pressure heads.

On the base of obtained results, in the analysed WDS three different types of priority zones were marked, which are presented in figure 9 . The zone of high priority was estimated mainly in areas of low pressure head with small pipes diameters. In high priority zones, it is strongly recommended to systematically implement software and hardware water loss detection methods. In medium priority zones the occasional application of hardware tools should be sufficient, while in low priority zones software methods should be efficient enough.

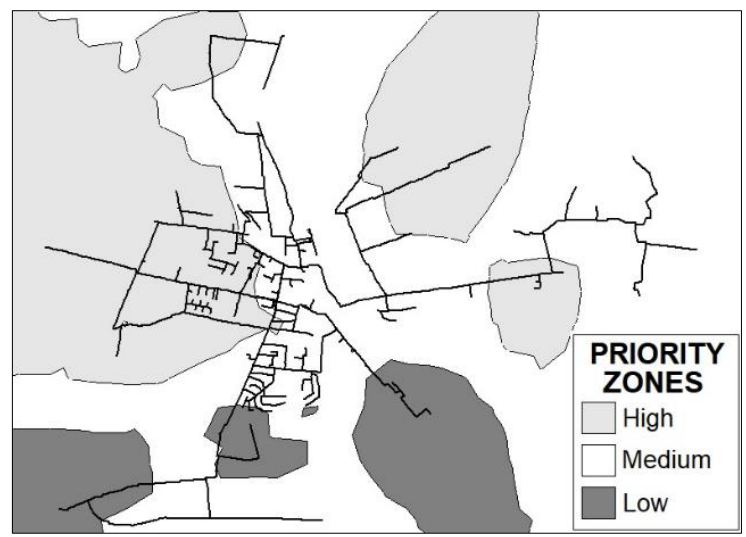

Fig. 9. Water losses priority zones of the analysed WDS.

\section{Conclusion}

The obtained results confirmed the expected conclusions that time of water outflow increases simultaneously with diminishing the leak area and pressure head. In the article, the most unfavourable case of possible leak area was taken into account (water leaking on the whole pipe circuit) which resulted in relatively short water time outflow. In real conditions, pipe holes which occur during pipe breakages are often of a smaller size - which will probably result in higher water outflow time and bigger water losses. Moreover, in these investigations it was assumed that water will always outflow to the soil surface, but it does not always happen in real soil conditions.

Dividing WDS into zones of different priorities of applying software and hardware methods of water losses detection may be helpful for the water company in developing the most efficient water losses strategy reduction. FEFLOW software is a very useful tool to estimate the water time outflow without laboratory examinations. In the case of analysed WDS, it is highly recommended that zones of high priority should be regularly monitored because of a high possibility of significant water losses during the occurrence of background leakages. Areas of a low pressure should be monitored the most carefully, because the potential pipe failure may be invisible on the soil surface and therefore may result in long-term water leakage.

In general, water companies should individually develop a water losses reduction strategy together with establishing the acceptable economical level of water losses. It is worth remembering, that a small level of real losses results not only in economic benefits of the company, but also positively influences on the company's social perception. Customers are not obligated to pay for the water losses and the company may demonstrate that the environment protection and realization of sustainable development principles are essential points of the company's managing policy.

\section{References}

1. World Bank Press Release: www.worldbank.org/en/ news/press-release/2016/09/01/the-world-bank-andthe-international-water-association-to-establish-apartnership-to-reduce-water-losses [access 8.08.2017]

2. L. Berardi, D. Laucelli, R. Ugarelli, O. Orazio Giustolisi, Procedia Eng. 119(1) (2015)

3. M. Iwanek, P. Suchorab, M. Karpińska-Kiełbasa, PERIOD. POLYTECH-CIV. 61(4) (2017) DOI: 10.3311/PPci.9728

4. J. Stańczyk, E. Burszta-Adamiak, D. Poor, GWiTS 5(91) (2017) DOI: 10.15199/117.2015.5.4 (in Polish)

5. Z.Y. Wu, M. Farley, D. Turtle, Z. Kapelan, J. Boxall, S. Mounce, S. Dahasahasra, M. Mulay, Y. Kleiner, Water Loss Reduction (Bentley Institute Press, 2011)

6. S. Speruda, Radecki R. Ekonomiczny poziom wycieków. Modelowanie strat $w$ sieciach wodociagowych (Warszawa: Translator S. C., 2007) (in Polish)

7. M.K. Widomski, D. Kowalski, M. Iwanek, G. Łagód, Modeling of Water Flow and Pollutants Transport in Porous Media With Exemplary Calculations in FEFLOW (Lublin University of Technology Monography, 2013)

8. P. Suchorab, B. Kowalska, D. Kowalski, Annu. Set. Env. Protection 18(2) (2016)

9. M. Iwanek, D. Kowalski, M. Kwietniewski, Ochrona Środowiska 37(4) (2015) (in Polish, with English abstract)

10. M. Iwanek, B. Kowalska, E. Hawryluk, K. Kondraciuk, Eksploat. Niezawodn. 18(2) (2016) DOI: 10.17531/ein.2016.2.16

11. J. E. van Zyl. Procedia Eng. 89 (2014) 